\title{
Study of fireproof properties of textile materials safe when in contact with human skin
}

\author{
Natalia Konstantinova ${ }^{1}$, Tatyana Eremina $^{2 *}$ and Irina Kuznetsova ${ }^{3}$ \\ ${ }^{1}$ FGU VNIIPO Russian Emergency Control Ministry, Moscow, Russia \\ ${ }^{2}$ Moscow State University of Civil Engineering, Yaroslavskoe shosse, 26, Moscow 129337, Russia \\ ${ }^{3}$ MNIC S\&PB Ltd /St. Petersburg, Russia
}

\begin{abstract}
The methods of surface fire retardant treatment of textile materials (TM) and the chemical basis of the fire retardants used are considered. The possibility of developing a fire retardant composition for tissues that would not adversely affect the human skin upon contact has been studied. To determine the degree of danger of contact and of the penetration of chemicals through skin in contact with the fireproof TM, special studies were conducted to study the local irritating effect and resorption of the composition according to special developed laboratory methodological instructions. As the result the evidence was found that the irritating effect of the fire retardant composition developed on the skin and mucous membranes of the eyes of experimental animals was not detected. Comparative thermo analytical studies showing the effectiveness of the fire retardant action of the composition developed on the main stage of thermal decomposition of cellulose-containing TM are presented. Thus, the development of a fire retardant composition based on phosphoruscontaining compounds and urea compounds and the selection of the optimum ratio of stabilizers for the processing of decorative and finishing fabrics with safe contact with human skin can be one of the effective ways to solve the problem under consideration.
\end{abstract}

\section{Introduction}

One of the effective ways to increase the resistance to ignition and reduce the spread of fire over the surface of textile materials (TM) without changing the chemical basis of the raw material of the fibers is their surface fire retardant treatment.

Surface fire retardant treatment of textiles on an industrial scale, and directly on sites is widely used and is the most accessible method in terms of technological capabilities, and sometimes the cost of components. The method consists in fixing the dissolved, emulsified, or suspended fire-retardant additive on the fabric and allows the use of fire retardants, which are part of the finishing preparations during its manufacture.

\footnotetext{
*Corresponding author: ICA_kbs@mgsu.ru
} 
Despite the popularity and wide use of various formulations designed to reduce the combustibility of TM from natural, chemical and mixed fibers, the development of new, more effective methods of fire protection is very relevant.

Quite often, working clothes, scenic decorations, upholstery of furniture and armchairs, as well as bedding are exposed to fire retardant surface treatment, therefore, along with giving TM fire retardant properties, it is also important to study the effect of the tissue on the human skin, during its use.

The most common TM on an industrial scale and the most effective in fire protection are impregnated compositions based on the use of phosphorus and nitrogen-containing compounds [1-3], as a rule, they process fabrics with a dominant cellulose component. The effect of phosphorus-containing fire retardants is usually attributed to the fact that pyrolysis of phosphorus-containing polymers produces phosphoric acid and its anhydrides that catalyze dehydration and dehydrogenation and contribute to the carbonization process, and the resulting carbonized layer, to a certain extent, hinders the yield of flammable combustion gases. It is also known that the use of various fire retardant compositions of this type can lead to a significant deterioration in the properties of the textile material: loss of strength, loss of decorative properties, increase in toxic products of thermal decomposition and smoke et al. [1].

However, one of the main disadvantages of these compounds is their instability, decomposition and dissociation in time, which can lead to irritation of the skin of a person when in direct contact with the fireproof material. Therefore, an important practical issue is to study the possibility of developing a fire retardant impregnation for tissue that does not adversely affect the human skin upon contact. It should be noted that this information is not available or has not been confirmed by scientific research on the currently available fire retardant impregnations on the market.

One of the possible solutions for the development of the composition for surface treatment of tissues can be the composition proposed by the authors, which allows not only to give them fire retardant properties, but also to avoid the irritation of the skin of a person in case of possible contact.

For this purpose, into a fire retardant composition for surface treatment of a fabric with a phosphorus-containing compound, carbamide and water is included, have been added lactones and a buffer solution of citric acid.

Compounds based on urea are widely used in compositions for fire protection of materials, at the same time urea is also used for the production of cosmetic and pharmaceutical products [4-8]. However, its main disadvantage is instability in neutral aqueous solutions and hydrolysis with the release of carbon dioxide, other amines and ammonia [9], which leads to the appearance of the odor of ammonia, a significant change in the $\mathrm{pH}$ of the medium to the alkaline side and, thus, adversely affects the functionality of the whole system as a whole. With the volatilization of ammonia, the fire-protective efficiency of the impregnating composition decreases, and its alkaline environment causes damage to the epidermis of the skin (in the form of irritation, reddening, itching). It can be assumed that the same nature processes take place in a fire retardant impregnation on TM, urea absorbs moisture from the air and, with time, begins to actively decompose.

To prevent the decomposition of urea in the solution (fire-retardant composition), as well as during the operation of the processed TM, a stabilizer system was introduced into the formulation, one of the constituents of which is lactone, and a buffer solution of citric acid is used to maintain the $\mathrm{pH}$ of the medium. Lactones possess many properties of noncyclic esters and are widely used in cosmetic preparations for the stabilization of urea. The mechanism of action of this system is not fully understood, and the authors did not set the goal of this work to carry out fundamental studies of ongoing processes. However, one can make the assumption that in this case the LeChatelier-Brown principle comes into play, so, 
in the decomposition of lactones, carbon dioxide is formed, which shifts the concentration limits of urea towards binding of molecules. Another suggestion may be the formation of a deep eutectic solution between carbamide and lactone, which helps to keep the urea molecule from degradation upon ingress of moisture [10 - 15].

\section{Methods}

To maintain urea-based compounds in a stable state, experimental studies using lactones were carried out. During the experiments, various concentrations of lactone were added to solutions containing $30 \%$ of urea-based compounds and the change in acid-base equilibrium ( $\mathrm{pH}$ of the medium) was monitored. Samples of the solutions were kept at a constant temperature of $45^{\circ} \mathrm{C}$ in a drying cabinet for 90 days, with measurements of the $\mathrm{pH}$ of the medium once a day and of the concentration of salts by means of a conductometer.

The results of the experiments showed that all the solutions with lactone retained the $\mathrm{pH}$ of the medium from 5.5 to 7 , which is quite an acceptable property for the development of fire retardant impregnation of tissue, taking into account possible contact with the human skin. It should be noted that $\mathrm{pH}$ values of sample solutions with $30 \%$ urea content without lactone addition significantly increased. So, 10 days after the beginning of the experiment, the $\mathrm{pH}$ of the solution was 8.6, after 20 days -8.9 , and after 45 days the $\mathrm{pH}$ level exceeded 9.3. In addition, in solutions containing lactone, the smell of ammonia was completely absent, which characterizes the stability of urea-based compounds, while in the sample formulations of solutions without the addition of lactone there was a tangible smell of ammonia, indicating the disintegration of carbamides.

\section{Results}

The results of experimental studies of aqueous solutions with $50 \%$ urea content showed that the rate of $\mathrm{pH}$ change is significantly influenced by the ambient temperature. For example, samples of solutions cured at $45^{\circ} \mathrm{C}$ reached a $\mathrm{pH}$ equal to the $\mathrm{pH}$ level of the samples cured at $37^{\circ} \mathrm{C}, 2-3$ times faster and much more rapidly than solutions stored at room temperature.

Figure 1 shows a plot of the $\mathrm{pH}$ versus time in solutions of samples with a different lactone content with a urea content of $1 \%$.

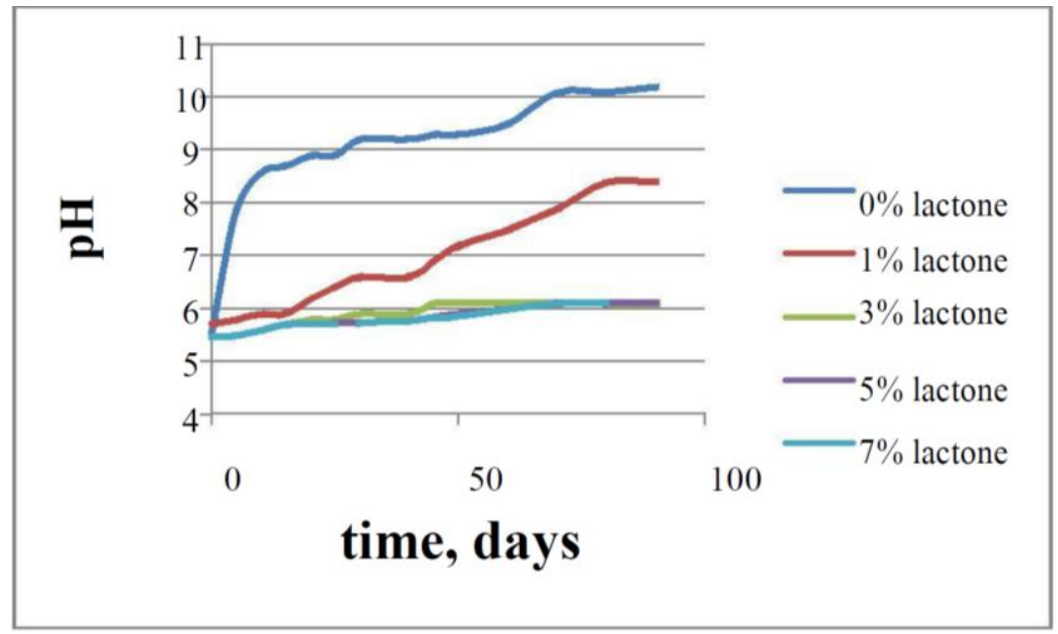

Fig. 1. Dependence of $\mathrm{pH}$ of solutions on time at various concentrations of lactone. 


\section{Discussion}

With an increase in the concentration of lactone in the system, the $\mathrm{pH}$ value of the hydrogen during the curing of the samples does not increase significantly in the alkaline side. Samples with a low lactone content, or without it, sharply gain a high $\mathrm{pH}$ level.

To determine the degree of hazard during the contact with a fire-retardant TM and the penetration of chemicals through the skin, special studies were conducted of the local irritating effect and of the resorption of the formulation using the developed laboratory guidelines [16-21].

To assess the adverse side effect of the developed composition on skin integuments of a living organism, preliminary tests were carried out on warm-blooded sexually mature animals - white rats weighing 210-220 g, white mice weighing 23-25 g and guinea pigs weighing 480-500 g.

The results of the studies are presented in Table 1.

Table 1. Results of studies on the evaluation of the effect of the composition on the animal organism.

\begin{tabular}{|c|c|c|}
\hline Defined indicators & $\begin{array}{c}\text { Measurement } \\
\text { Units }\end{array}$ & Results of studies \\
\hline $\begin{array}{l}\text { Inhalation hazard Using a } \\
\text { static Inhalation primer, } \\
\text { CL50 (nos), exposure is } 2 \\
\text { hours white mice) }\end{array}$ & Мг/м3 & $\begin{array}{l}\text { Volatile components do not cause irritation } \\
\text { of the mucous membranes of the eyes and } \\
\text { upper respiratory tract (tremor, lateral } \\
\text { position). } \\
\text { Animal death was not observed. } \\
C L<50000\end{array}$ \\
\hline $\begin{array}{l}\text { Skin irritation (white rats) } \\
\text { - onetime } \\
\text { - repeated }\end{array}$ & points & $\begin{array}{l}0 \\
0\end{array}$ \\
\hline $\begin{array}{l}\text { Irritant effect on the mucous } \\
\text { membranes of the eyes } \\
\text { (Guinea pigs) }\end{array}$ & points & 0 \\
\hline $\begin{array}{l}\text { Skin Restorative Action } \\
\text { (white mice) }\end{array}$ & - & Not found \\
\hline $\begin{array}{l}\text { Sensitizing } \\
\text { effect } \\
\text { (DSR - white mice) }\end{array}$ & points & 0 (Not found) \\
\hline
\end{tabular}

Evaluation of the severity of irritant properties was carried out according to the classification defined in the methodical order of the research of normative documents. As follows from the research results, the irritant effect of the developed fire retardant composition on the skin and mucous membranes of the eyes of the experimental animals was not revealed.

To study the process of thermal destruction in the presence of fire retardants, comparative experiments were carried out on the derivatographic equipment to establish the temperature range of the processes of thermal oxidative decomposition of fire-retardant TM.

Samples of half-holland fabric were used with a surface density of $380 \mathrm{~g} / \mathrm{m}^{2}$, treated with various fire-retardant compounds of phosphoric acid derivatives (a widely used on an industrial scale MS-T composition, which is an aqueous solution of ammonium salts of phosphoric acid and ammonium sulphate, and the composition developed by the authors Arterma").

The application to the textile material of $20 \%$ of the MC-T impregnating composition can be carried out according to a known process scheme by brush, roller, immersion or 
spraying. After impregnation by the immersion method, the material is extracted to $80-90 \%$ and then dried at a temperature of $100-150^{\circ} \mathrm{C}$. It should be noted that the fire-retardant composition of MC-T is produced serially and has a certificate of compliance with fire safety requirements.

The impregnating fire-retardant composition "Arterma" is delivered in a completely ready to use form, with a mass fraction of non-volatile components of $15 \%$. The composition can also be applied to TM in various ways: by brush, roller, immersion or spraying. The drying process of the treated material can take place at room temperature, i.e. natural conditions, and the composition consumption for achieving the effect of fire protection depends on the type and $\mathrm{m}^{2}$.

the surface density of the fabric and the structure of the material is from 100 to $500 \mathrm{~g} /$

In this case, the consumption of compositions for surface treatment of half-holland was, respectively, MS-T - $70 \mathrm{~g} / \mathrm{m}^{2}$, and in "Arterma" $45 \mathrm{~g} / \mathrm{m}^{2}$.

Comparative studies of the effectiveness of the fire retardant effect of the compositions in the condensed and gas phases during the thermal decomposition of the treated tissues were carried out using the method of thermogravimetric analysis, which makes it possible to obtain information on the ranges and rates of decomposition of the material.

Analysis of thermoanalytical data (Table 1) showed that the thermal destruction of the original cellulose-containing tissue is accompanied by two maxima of DTG mass loss rates in the temperature range of $340-350 \mathrm{C}$ and $440-470^{\circ} \mathrm{C}$. Treatment of the fabric with fire retardants made it possible to obtain fire-retardant compositions of TM, and according to their thermoanalytical studies, for fire-retardant fibers, the smoothed DTG peaks of thermodegradation curves are characteristic, which is associated with a smoother loss of mass, while oxidation rates are significantly lower compared to unprotected tissue, and the thermooxidation process itself shifts to higher temperatures.

Comparative results of differential thermal analysis of tissue samples are presented in Table 2.

Table 2. Comparative results of differential thermal analysis of tissue samples.

\begin{tabular}{|l|c|c|c|}
\hline $\begin{array}{c}\text { The characteristic } \\
\text { points Of the DTG } \\
\text { curves }\end{array}$ & Initial tissue & $\begin{array}{c}\text { Initial tissue + } \\
\text { MC-T 20\% }\end{array}$ & $\begin{array}{c}\text { Initial tissue + } \\
\text { Arterma15\% }\end{array}$ \\
\hline $\begin{array}{l}\text { Mass loss, \% temp. } \\
\text { interval } \\
30-150^{\circ} \mathrm{C} \\
150-350^{\circ} \mathrm{C}\end{array}$ & 3.2 & 3.8 & 6.7 \\
$350-850^{\circ} \mathrm{C}$ & 94.3 & 53.3 & 56.0 \\
\hline The Ash Residue & 2.5 & 3.5 & 3.1 \\
\hline DTG Maxima: $\mathrm{T},{ }^{\circ} \mathrm{C}$ & & & $244 / 9.8$ \\
\hline 1 & $350 / 63.7$ & $267 / 21.9$ & $271 / 50.5$ \\
\hline 2 & $450 / 1.3$ & $306 / 24.4$ & $498 / 2.36$ \\
\hline 3 & & $483 / 3.7$ & \\
\hline
\end{tabular}

As it follows from the data presented (Table 2), the formulations studied are effective enough to reduce the inflammability of the cellulose-containing tissue. This is confirmed by the possibility of obtaining materials that are resistant to the action of an open fire according to the procedure [17] with the indicated compositions. However, the achievement of the fire protection effect occurs at different consumption and concentrations of the compounds with the same treatment technology, which indicates some advantage of the Arterma composition (in the given studies it has a lower consumption and concentration), the treatment with Arterma practically does not change the color and appearance of the 
tissue. Yet, when using the MS-T, the appearance of the tissue changed: salt stains emerged and sometimes it irritated the human skin, when in contact to it, causing its reddening.

As a rule, the use of fire protection means increases the yield of gaseous products of thermal decomposition and smoke-forming ability with a sufficiently effective decrease in the flammability of TM.

In this case, without having a negative effect on the human skin, the developed fire retardant composition not only effectively reduces inflammability, which is confirmed by the production of fire-retardant tissues with a dominant cotton component, but also there is no increase in their smoke-generating capacity nor the release of toxic gaseous products of thermal decomposition(Table3).

As a criterion for evaluating the effect of fire retardant composition on the yield of gaseous products of thermal decomposition of TM, a comparison was made of the values of the yield of carbon monoxide (CO) and carbon dioxide (CO2) in the thermal decomposition regime according to the standard procedure [8] (\$4.20), with the difference that the conducted studies on the release of toxic gaseous products of thermal decomposition of fireretardant and initial fabrics were related not to the mass, but to the area of the material sample $80 \times 80 \mathrm{~mm}$ in size. The smoke production coefficient was estimated by the standard method [8] (4.18) in the smoldering regime, which is the most dangerous.

Table 3. Results of studies of fire hazard indicators of fireproof TM.

\begin{tabular}{|l|c|c|c|c|}
\hline \multicolumn{5}{|c|}{ The toxicity and smoke-forming ability of flame-retardant tissues } \\
\hline \multicolumn{2}{|c|}{ Tissue composition, $\%$} & Flammability & $\begin{array}{c}\text { Smoke } \\
\text { production } \\
\text { coefficient, } \\
\mathbf{m}^{2} / \mathbf{k g}\end{array}$ & $\begin{array}{c}\text { Combustion } \\
\text { products toxicity } \\
\mathbf{~ m g / g r} \\
\text { CO output }\end{array}$ \\
\hline $50 \%$ linen & initial & Highly flammable & 900 & 127 \\
\hline $50 \%$ cotton & treated & Un flammable & 780 & 102 \\
\hline $35 \%$ cotton & initial & Highly flammable & 1100 & 118 \\
\hline $65 \%$ polyether & treated & Un flammable & 980 & 85 \\
\hline
\end{tabular}

From the obtained results of the studies presented in Table 3, it follows that the fire retardant composition influences the direction of thermolysis of fire retardant tissues, contributing to a decrease in the amount of released $\mathrm{CO}$ and $\mathrm{CO} 2$, including fabrics with a polyester component. The experimental data obtained for smoke formation coefficients for the Arterma-protected tissues indicate a decrease in the numerical values in comparison with the coefficients of smoke formation of the initial tissue.

\section{Conclusions}

Thus, from the results of the conducted experimental studies it follows that the development of a composition based on phosphorus-containing compounds and urea compounds and the selection of the optimum ratio of stabilizers can be one of the effective ways of solving the problem of surface fire-retardant treatment of decorative and finishing tissues with safe contact with human skin.

The developed composition TM for fire retardant treatment along with ensuring safety of contact with the human skin enables us to obtain effective fire-retardant materials, without increasing the emission of toxic volatile components of thermal decomposition and smoke-forming ability. 


\section{References}

1. N.S. Zubkova, N.I. Konstantinova, Fire protection of textile materials, Moscow: Institute of Information Technologies, 228 p. (2008)

2. A. Khvala, V.Anger, Textile auxiliary substances, vol. 2, p.147-171\5. (1991)

3. V.I. Besshoposhnikova, O.N. Mikryukova, M.V. Zagoruiko, V.A. Steinle "Fire protection of mixed fabrics with a phosphorus-containing flame retardant system", "Bulletin of the Technological University" vol.20, no. 22, p. 69-72, (2017)

4. K.S. Guzev, O.L. Zheltovskaya, V.I. Notherdin "Ointment Ointment containing 30\% of urea, a domestic medicinal product that increases the moisture of dry skin", Dermatology of Russia, S1, 42 p. (2017)

5. A.V. Gorchak, K.A. Ivanov, A.A. Nikitin, G.I. Pashintsev "Cream-lifting from wrinkles", patent No. 2207111, (2003)

6. O.V. Udovichenko "The Role of Urea Preparations for Topical Use in the Prevention of Lower Limb Infections in Patients with Diabetes Mellitus", "Effective Pharmacotherapy", No. 39, p. 4-9. (2014)

7. E.S. Savchenko, V.V. Verderenko, V.R. Khayrutdinov et al., "Experience in the use of Glatte external agent (5\% urea cream foam) in the treatment of patients with atopic dermatitis," Effective Pharmacotherapy ", No. 33, p. 4-9. (2015)

8. N.N. Filimonkova, E.A. Bakhlykova "Topical glucocorticosteroid and $2 \%$ urea - a new remedy for external therapy of chronic dermatoses", "Clinical dermatology and venereology", v. 14, №6, p. 35-40. (2015)

9. Lurie Yu.Yu. "Handbook of Analytical Chemistry., 4th Edition.",. Moscow. Chemistry, C.254, (1971)

10. L.E. Znjakina, M.L. Tkachenko, Yu.V. Moschensky, I.P. Ivanova "Phase equilibria of ibuprofen in systems with pyracetam and urea as hydrophilic constituents", "ChemicoPharmaceutical Journal", v. 42, No. 12, p. 44-46 (2008)

11. Sh.Sh. Khamdamova, M.K. Askarova, S. Tukhtaev "Interaction of components in the water system with the participation of calcium dicarbamidochlorate and carbamide phosphate", European Research, No. 10 (21), 10-12. (2016)

12. Dmitry Korolchenko, Behavior of bearing reinforced concrete panels in the process of combined action // MATEC Web of Conferences 265, 05037 (2019)

13. Polandov Iu., Korolchenko D. The consideration of the turbulence influence on the gas explosion expansion in non-closed areas. MATEC Web of Conferences, vol. 106, article number 01040, 8 p. DOI: 10.1051/matecconf/201710601040 (2017)

14. Kholshchevnikov V., Korolchenko D., Zosimova O. Efficiency evaluation criteria of communication paths structure in a complex of buildings of maternity and child-care institutions. MATEC Web of Conferences, vol. 106, article number 01037, 11 p. DOI: 10.1051/matecconf/201710601037 (2017)

15. Korolchenko, D., Pizhurin, A., Simulating operational control of production in lumber house building businesses S.Jemiolo et al.,eds. MATEC Web of Conferences, 117, p.00084. DOI: $10.1051 /$ matecconf/201711700084. (2017)

16. MU No. 2163-80 the design of the studies to justify the sanitary standards of harmful substances in the air of the work area.

17. Instruction 1.1.11-12-35-2004 Requirements for the design of experimental studies for primary toxicology assessment and hygienic assessment and hygienic regulation of substances.

18. MU 2102-79 Assessment of the impact of harmful chemical compounds on the skin and the rational for the maximum permissible levels of skin contamination 
19. MU 2196-80 Methodological instructions for the design of studies of irritant properties and the justification of the maximum permissible concentrations of selectively acting irritants in the air of the working area.

20. MU 1.1.578-96 Requirements for the design of experimental studies on the justification of the maximum permissible concentrations of industrial chemical allergens in the air of the working zone and the atmosphere.

21. GOST R 50810-95 Fire safety of textile materials. Decorative fabrics. Test method for flammability and classification. 